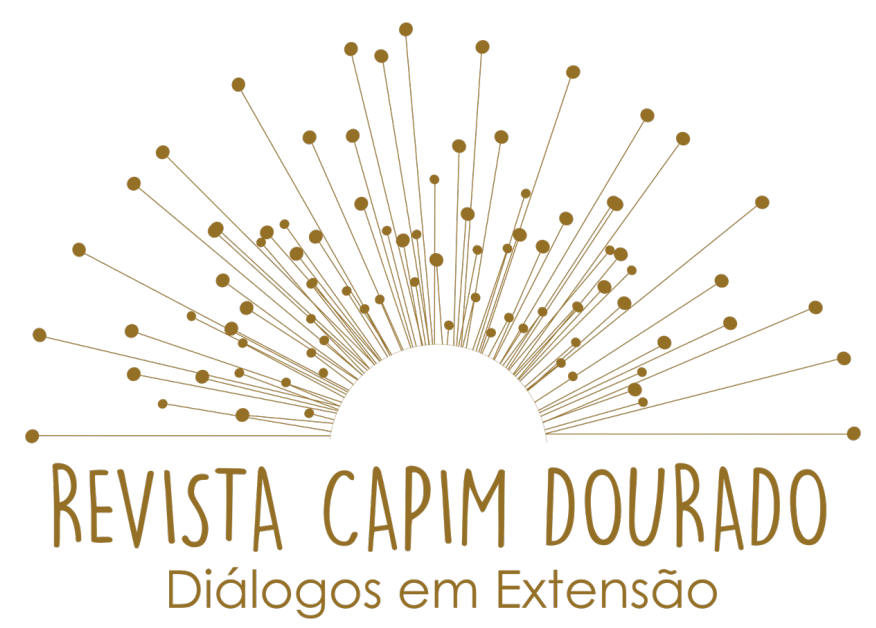

ISSN n² 2595-7341

Vol. 3, n. 1, Janeiro-Abril, 2020

DOI: http://dx.doi.org/10.20873/uft.2595-7341.2020v3n1p210

\title{
INVENTAR COM A DIFERENÇA: uma experiência em Arraias -
}

\section{Tocantins}

Invent with difference: an experience in Arraias -Tocantins

Inventar con la diferencia: una experiencia en Arraias -Tocantins

\section{João Nunes da Silva ${ }^{1}$}

\section{RESUMO}

Este trabalho trata de cinema e teve como objetivo estimular os estudantes da Escola pública a produzirem vídeos e fotografias a partir da realidade. Foram realizadas oficinas com estudantes e professores da Escola Silva Dourado e da UFT Campus de Arraias sobre como ler fotografias e produzir vídeos. O projeto se insere na proposta Inventar com a diferença- Cinema e direitos humanos, tendo como base uma cartilha didática produzida pela Universidade Federal Fluminense. Foram realizadas ao todo 16 oficinas sendo $10 \mathrm{com}$ professores e estudantes da UFT e 6 na Escola. A experiência foi bastante proveitosa para aproximar Universidade e Comunidades escolares bem como para favorecer a reflexão sobre os Direitos Humanos, os quais correspondem, a tudo o que está relacionado a vida humana.O uso do cinema tem sido usado como um recurso fundamental para discutir a vida e suas diferentes nuances, principalmente quando se tratam de Direitos Humanos. O projeto desenvolvido nas escolas e universidade, conforme pudemos constatar além de aproximar estudantes e professores da prática cinematográfica favoreceu um olhar poético sobre a vida humana e tudo o que a rodeia a partir da realidade.

\footnotetext{
${ }^{1}$ Doutor em Comunicação e cultura contemporâneas e Professor do curso Serviço Social da UFT. E-mail: joao.ns@uft.edu.br.
} 


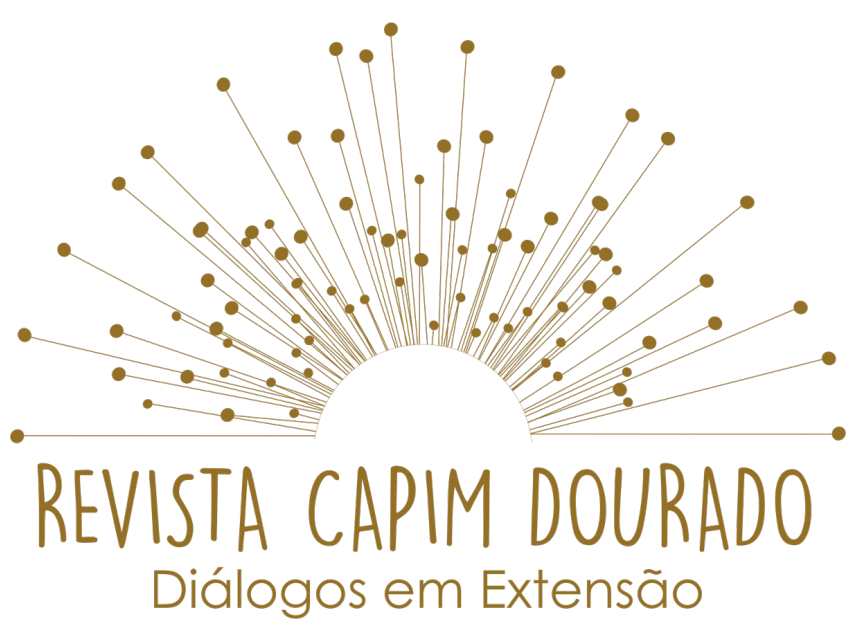

ISSN n² 2595-7341

Vol. 3, n. 1, Janeiro-Abril, 2020

DOI: http://dx.doi.org/10.20873/uft.2595-7341.2020v3n1p210

PALAVRAS-CHAVES: Inventar com a diferença. Cinema. Direitos humanos. Fotografias.

\begin{abstract}
This work it's about cinema and aimed to stimulate public school students to produce videos and photographs from reality. Workshops were performed with students and teachers at the Escola Silva Dourado and UFT Campus de Arraias on how to read photographs and produce videos. The project is part of the proposal Inventing with Difference - Cinema and human rights, based on a didactic primer produced by Federal Fluminense University. A total of 16 workshops were carried out, of which 10 were professors and students from UFT and 6 were from the School. The experience was very useful to approach University and School communities as well as to promote reflection on Human Rights, which correspond to everything that is related to human life. Cinema has been used as a fundamental resource to discuss life and its different nuances, especially when it comes to Human Rights. The project developed in schools and universities, as we could see, besides bringing students and teachers closer to the cinema, has favored a poetic look at human life and everything that surrounds it from reality.
\end{abstract}

KEYWORDS: Invent with difference.Cinema. Human rights. Photography.

\title{
RESUMEN
}

Este trabajo trata de cine y tuvo como objetivo estimular a los estudiantes de la Escuela pública a producir videos y fotografías a partir de la realidad. Se realizaron talleres con estudiantes y profesores de la Escuela Silva Dourado y de la UFT Campus de Arraias sobre cómo leer fotografías y producir vídeos. El proyecto se inserta en la propuesta Inventar con la diferencia- Cine y derechos humanos, teniendo como base una cartilla didáctica producida por la Universidad Federal Fluminense. Se realizaron en total 16 talleres siendo 10 con profesores y estudiantes de la UFT y 6 en la Escuela. La experiencia fue bastante provechosa para acercar a la universidad y las comunidades escolares, así como a favorecer la reflexión sobre los derechos humanos, que corresponden a todo lo relacionado con la vida humana. El uso del cine ha sido utilizado como un recurso 


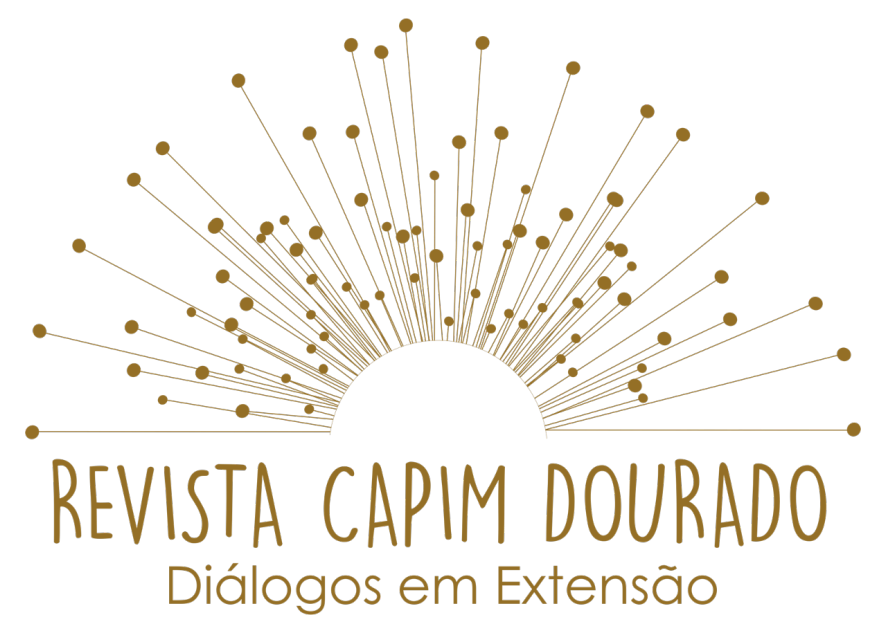

ISSN n² 2595-7341

Vol. 3, n. 1, Janeiro-Abril, 2020

DOI: http://dx.doi.org/10.20873/uft.2595-7341.2020v3n1p210

fundamental para discutir la vida y sus diferentes matices, principalmente cuando se trata de derechos humanos. El proyecto desarrollado en las escuelas y la universidad, como pudimos constatar además de acercar a estudiantes y profesores de la práctica cinematográfica, favoreció una mirada poética sobre la vida humana y todo lo que la rodea a partir de la realidad.

Deve conter entre 100 a 250 palavras. Deve ressaltar tema, objetivos, métodos, resultados e conclusões, em único parágrafo, escrito em corpo 12, fonte times e espaço simples.

PALABRAS CLAVES: Inventar con la diferencia. Cine. Derechos humanos. Fotos.

Recebido em: 01.10.2019. Aceito em: 09.10.2019. Publicado em: 01.01.2020. 


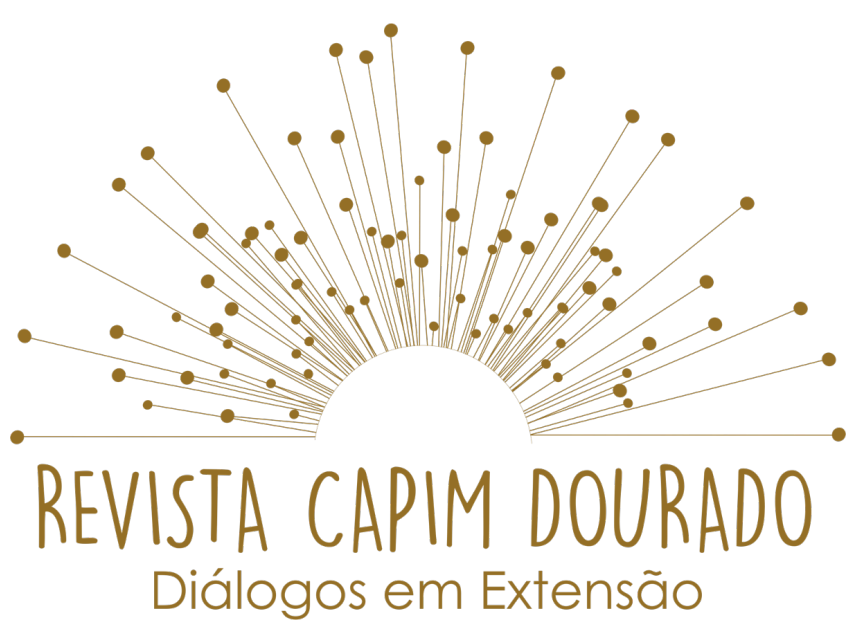

ISSN n² 2595-7341

Vol. 3, n. 1, Janeiro-Abril, 2020

DOI: http://dx.doi.org/10.20873/uft.2595-7341.2020v3n1p210

\section{Introdução}

O Projeto Cinema e Direitos Humanos nas escolas- Inventar com a diferença visa aproximar Universidade e Sociedade. É uma ação em parceria com as escolas públicas do Tocantins envolvendo a comunidade Acadêmica dos cursos da Universidade Federal do Tocantins - UFT, pesquisadores do Núcleo de Pesquisa e Extensão Observatório de Pesquisas Aplicadas ao Jornalismo e ao Ensino- OPAJE, e do Núcleo de Pesquisa em Educação, Comunicação e Cultura NUPECC, situados em Palmas e Arraias no Estado do Tocantins. Os Objetivos específicos foram: organização de oficinas sobre cinema e vídeo como preparação para os alunos e professores das escolas produzirem audiovisuais relacionados a questão dos direitos humanos no contexto nacional e local, considerando a realidade do Tocantins; capacitar os estudantes para o uso da linguagem audiovisual, despertando para explorar e compartilhar saberes e práticas em torno da relação cinema e direitos humanos; aprender como se faz leitura de imagens, produção de fotografias, análise de planos e minuto Lumière.

Utilizamos como material básico para a execução do projeto os "Cadernos do Inventar-Cinema, educação e Direitos Humanos", elaborados por Cezar Migliorin, Isaac Pipano e outros autores (2016), da Universidade Federal Fluminense. Tal experiência é fruto de longas discussões a partir do ano de 2014 que "constituiu uma rede de educadores nos 26 estados brasileiros e Distrito Federal". O referido Caderno contém noções básicas para o uso de audiovisual e cinema, com destaques para metodologias e exercícios práticos. 


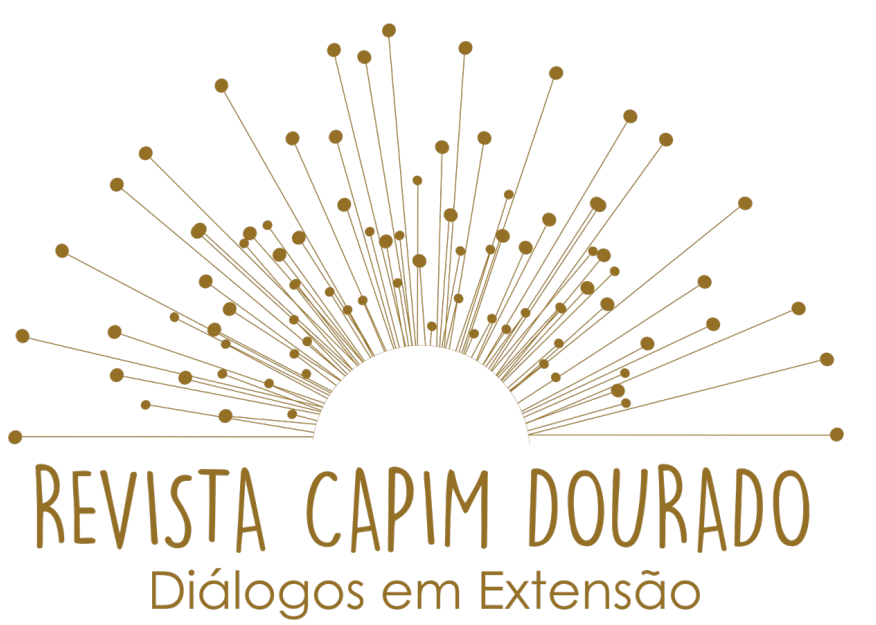

ISSN n² 2595-7341

Vol. 3, n. 1, Janeiro-Abril, 2020

DOI: http://dx.doi.org/10.20873/uft.2595-7341.2020v3n1p210

Priorizamos nas oficinas as dicas diversas sobre como trabalhar 0 audiovisual a partir das experiências de vida dos estudantes das escolas e sua realidade local. Em Arraias realizamos primeiramente dez encontros com estudantes do curso de Pedagogia e Turismo do Campus Universitário Sergio Jacintho Leonor. Os estudantes foram escolhidos conforme o interesse e disponibilidade para participar do projeto através do Núcleo de Pesquisa em educação, Comunicação e Cultura - NUPECC. O projeto desenvolvido nas escolas e universidade, conforme pudemos constatar além de aproximar estudantes e professores da pratica cinematográfica favoreceu um olhar poético sobre a vida humana e tudo o que a rodeia a partir da realidade.

\section{Resultados e discussão}

As oficinas foram divididas em dois momentos: uma com estudantes e professores da UFT e outra com estudantes da Escola Silva Dourado na cidade de Arraias-TO. As realizadas na UFT contaram com 20 vinte participantes, incluindo alunos de Pedagogia e de Turismo mais dois professores. Foram realizados dez encontros de quatro horas, totalizando uma carga horária de 40 horas. Esses encontros na Universidade aconteceram como forma de preparação da equipe para atuar nas escolas com o projeto. Foram trabalhados os seguintes aspectos: O projeto Inventar com a diferença; Experimentar o cinema: planos, Leitura de imagens: imagem: olhar e inventar, 2. Leitura de fotografias produzidas pelos estudantes; Olhar e inventar: como se vê? O que se vê? O que não se vê? 3. Minuto Lumiére: preparação e realização ; 4.Minuto Lumiere: Socialização das 


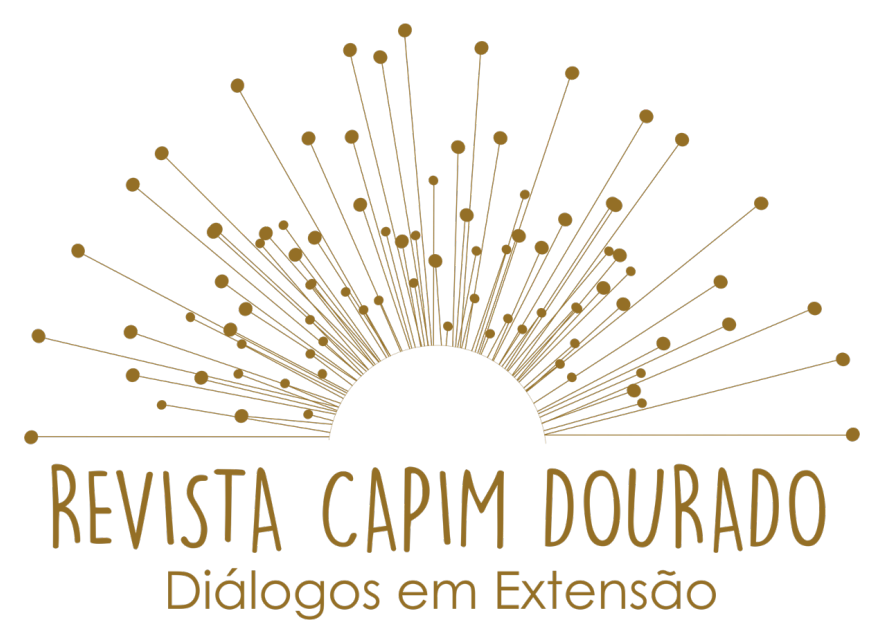

ISSN n² 2595-7341

Vol. 3, n. 1, Janeiro-Abril, 2020

DOI: http://dx.doi.org/10.20873/uft.2595-7341.2020v3n1p210

produções; 5. Análise de planos: experimentar o cinema; 6. Realização de Fotografia Narrada; 7. Apresentação e discussão das fotografias narradas; 8. Preparação para realização de filme carta; 9. Realização de filme carta; 10. Socialização das experiências do filme carta. A metodologia utilizada foi por meio de aulas expositivas e práticas com o uso de câmeras, celulares, câmera digital, projetor multimídia, DVD, caixas de som e notebook.

A oficina realizada com professores e estudantes da Universidade Federal do Tocantins, Câmpus de Arraias, contribuiu significativamente para aproximar professores e estudantes, além do conhecimento dos fundamentos para a produção e o uso de fotografias e de vídeos. A partir dessa experiência com as oficinas testemunhamos o aprendizado adquirido para o trabalho com os estudantes das escolas publicas com a temática cinema e direitos humanos.

\section{Oficinas na Escola Estadual Silva Dourado em Arraias-TO}

Após a realização das oficinas na UFT Campus de Arraias foi definido que o próximo passo seria visitar as escolas da cidade e agendar as primeiras oficinas com estudantes das escolas publicas. A princípio a prioridade foi trabalhar com as escolas mais próximas da Universidade. Uma das escolas que fizemos parceria num primeiro momento foi a Escola Estadual Silva Dourado, que trabalha com estudantes. A escola fica localizada no centro da cidade de Arraias e atua com ensino fundamental e Educação de jovens e adultos - EJA. Na escola participaram das oficinas cerca de 20 alunos, incluindo ensino fundamental e EJA. 


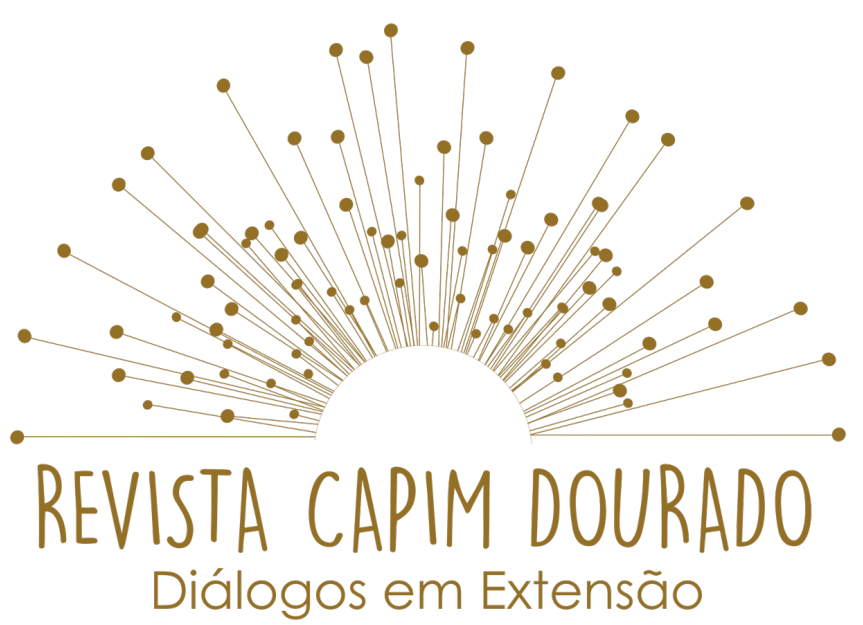

ISSN n² 2595-7341

Vol. 3, n. 1, Janeiro-Abril, 2020

DOI: http://dx.doi.org/10.20873/uft.2595-7341.2020v3n1p210

Os estudantes da escola aprenderam a fazer leitura de imagens e a fotografar a partir das escolhas. Na oportunidade da apresentação das fotografias tiradas pelos estudantes se percebeu a alegria e a dedicação dos participantes; na oportunidade fotografaram espaços de lazer, pessoas, casas e ruas, flores, quintais e jardins.

O momento da socialização das fotografias foi pedido que cada participante falasse sobre suas impressões com as fotografias tiradas, oportunidade na qual demonstraram ser muito importante saber o que fotografar e principalmente como fazer para valorizar mais o mundo que vivemos principalmente a realidade local que faz parte da vida de todos.

Os encontros seguintes foram trabalhados o minuto Lumière (vídeos de no máximo 1 minuto), planos, enquadramentos, movimentos de câmera e a fotografia narrada. Sobre o minuto Lumière foi destacada a historia do cinema inicado pelos irmãos Lumière, no século XIX, os quais realizaram $s$ primeira experiências com o uso de câmeras fixas, com filmes de no máximo um minuto.

As mesmas atividades realizadas com os estudantes e professores da universidade, foram trabalhadas na Escola Estadual Silva Dourado. Os estudantes da escola ficaram muito animados e produziram os filmes no modo do cinema Lumiere. Foi chamada a atenção para a importância desse tipo de filme como uma forma de apresentar com mais naturalidade possível os diversos aspectos do cotidiano e da vida. 


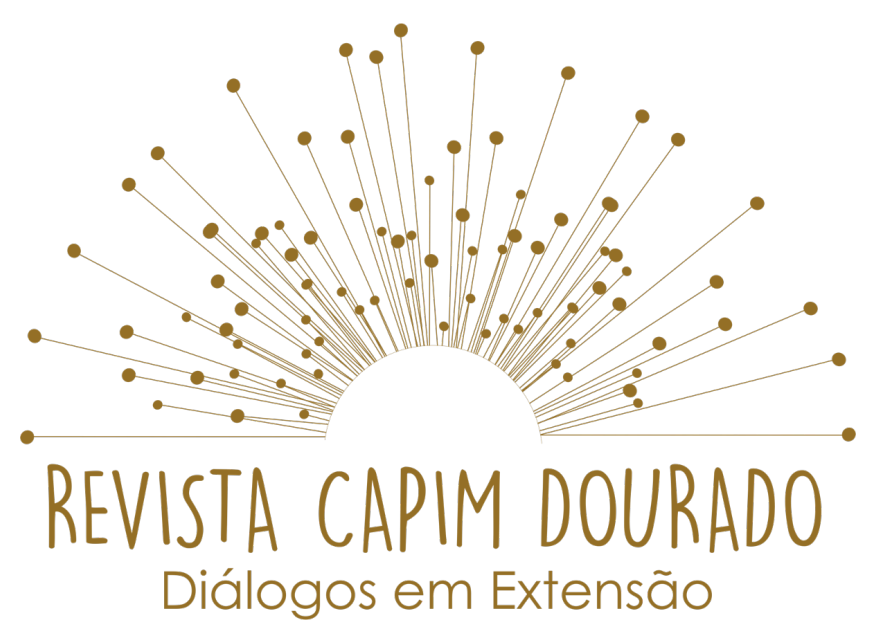

ISSN n² 2595-7341

Vol. 3, n. 1, Janeiro-Abril, 2020

DOI: http://dx.doi.org/10.20873/uft.2595-7341.2020v3n1p210

Na semana após as orientações de como fazer o cinema Lumière os estudantes participantes realizaram suas experiências para a gravação de filmes de no máximo um minuto utilizando câmeras de celulares e câmeras digitais.

Na socialização dos filmes Lumière os estudantes falaram da emoção de terem realizados essa tarefa de modo que alguns se sentiram orgulhosos e também, aprenderam valorizar mais os vários momentos da vida, do lugar em que vivem, das pessoas e das coisas em geral que fazem parte do mundo a sua volta.

Para a socialização de tudo o que foi produzido pelos alunos, além da apresentação em sala de aula, nas oficinas, foi criado o whatsapp com o nome da escola para socializar durante a semana. Fato que foi bastante proveitoso, pois a partir do que os alunos produziam e socializavam em rede, favoreceu o debate, as opiniões, elogios e até criticas, o que contribuiu para que cada participante do projeto pudesse aprimorar seus trabalhos.

O encontro seguinte foi a escolha do dispositivo da fotografia narrada; cada participante escolheu uma foto contar a sua historia. Essa experiência tem se revelado bastante proveitosa; no momento os alunos estão produzindo e apresentarão no encontro seguinte. Em seguida esse trabalho deve ser socializado com toda a comunidade da Escola Silva Dourado.

\section{Conclusões}

Após as experiências das oficinas do Projeto Cinema e Direitos Humanos - Inventar com a diferença, realizado com estudantes e professores da 


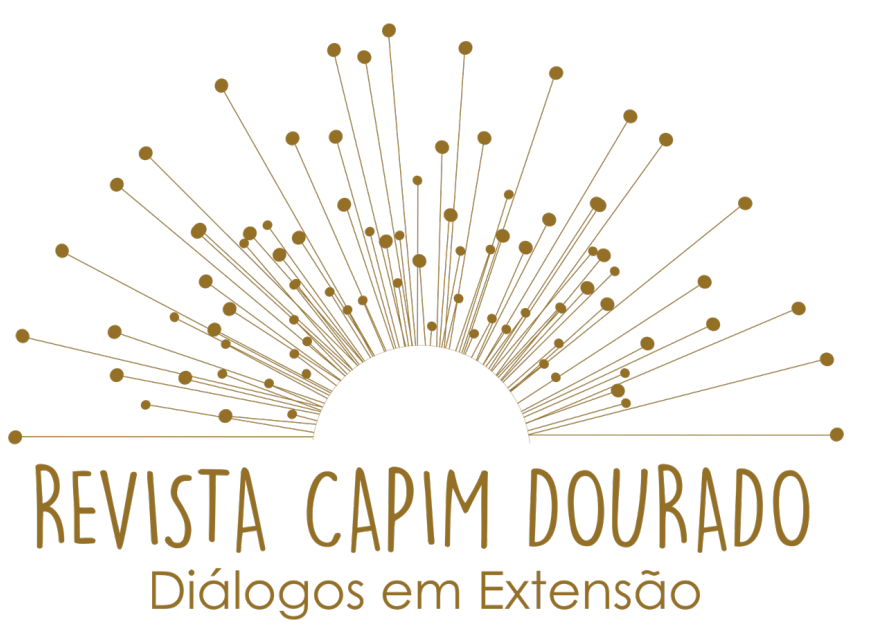

ISSN n² 2595-7341

Vol. 3, n. 1, Janeiro-Abril, 2020

DOI: http://dx.doi.org/10.20873/uft.2595-7341.2020v3n1p210

Universidade Federal do Tocantins e nas escolas da cidade de Arraias, conclui-se que tem sido bastante proveitosa para aproximar Universidade e Comunidades escolares bem como para favorecer a reflexão sobre os Direitos Humanos, os quais correspondem, a tudo o que está relacionado a vida humana.

Com o projeto desenvolvido nas escolas e universidade, conforme pudemos constatar, percebe-se o que podemos chamar de sensibilização humana, pois, favorece um oplhar poético sobre a vida humana e tudo o que a rodeia. A partir do moimento que as pessoas tem a possibilidade de conhecer as técnicas e os instrumentos necessários para fotografar os diversos momentos e aspectos da vida e, principalmente quando aprendem que fotografar e filmar seja o que for implica em fazer escolhas, logo, se percebe que podemos sim fazer um mundo melhor.

Com as experiências realizadas percebemos que Universidade e escolas é uma parceria indispensável para oportunizar novos olhares sobre a vida, especialmente para o exercício da cidadania de modo a desconstruir estereótipos criados numa sociedade instrumentalizada e movida pela ganância pelo poder e pelo dinheiro.

Aprender a fazer cinema a partir do cotidiano das coisas mais simples possíveis, como favorece o projeto Cinema e direitos humanos - Inventar com a diferença significa também aprender a olhar com mais atenção o mundo e oferecer oportunidades para os diferentes olhares.

Com as experiências realizadas percebemos que tudo o que aconteceu foi positivo, inclusive até mesmo alguns desencontros ou percalços tão comuns na 


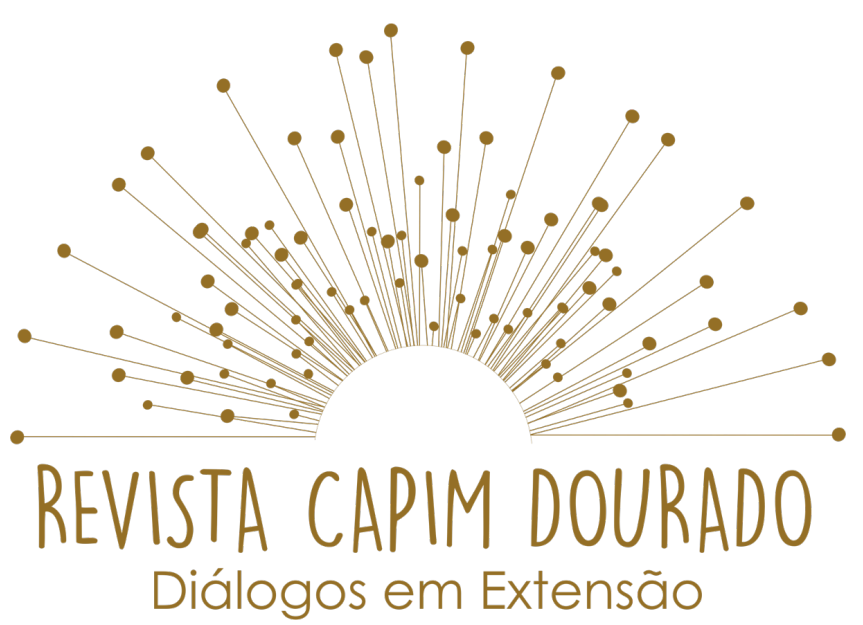

ISSN n² 2595-7341

Vol. 3, n. 1, Janeiro-Abril, 2020

DOI: http://dx.doi.org/10.20873/uft.2595-7341.2020v3n1p210

condição humana. A questão da integração escola e universidade é a primeira coisa que destacamos; em seguida vem a convivência com alunos e professores de escolas e da universidade, o empenho, a emoção que se percebe em cada produção, a realização de cada participante ao ver sua obra sendo destacada e comentada, entre outras realizações, mostra o quanto a universidade pode contribuir para uma sociedade melhor e mais humana a partir de projetos e ações como o Cinema e direitos humanos.

Por últimos destacamos que a experiência realizada, o material produzido, gerou debates e reflexões que certamente contribuirão para novas ações no sentido de valorizar mais a vida na nossa sociedade.

\section{Referências}

AGUILAR, C. Y.; GUNTHER, A. F. CINEMA E FOLKCOMMUNICATIONS: uma análise baseada no filme "Coco". Revista Observatório, v. 4, n. 5, p. 331-347, 1 ago. 2018. BARBOSA, C. TRAKINAGEM: cinema e educação na escola. Revista Observatório, v. 4, n. 4, p. 893-898, 29 jun. 2018.

DA SILVA, C. E. O USO DO CINEMA NO ENSINO DE HISTÓRIA EM CONSONÂNCIA COM AS NOVAS DEMANDAS DA HISTÓRIA PÚBLICA DIGITAL. Revista Observatório, v. 3, n. 5, p. 147-168, 1 ago. 2017.

DO NASCIMENTO, S. M.; COLLING, L. CORPOS DISSIDENTES: o documentário da subversão no interior do nordeste brasileiro. Revista Observatório, v. 2, n. 3, p. 28-42, 31 ago. 2016.

EVANGELISTA, F.; MARTINS , K. D.; ANGELINI, M. F. C.; ROCHA, M. J. F. SOCIEDADE DO CONHECIMENTO: $O$ uso das TIC por docentes e as novas articulações de saberes educacionais no sudeste do Pará. Revista Observatório , v. 5, n. 5, p. 188208, 1 ago. 2019. 


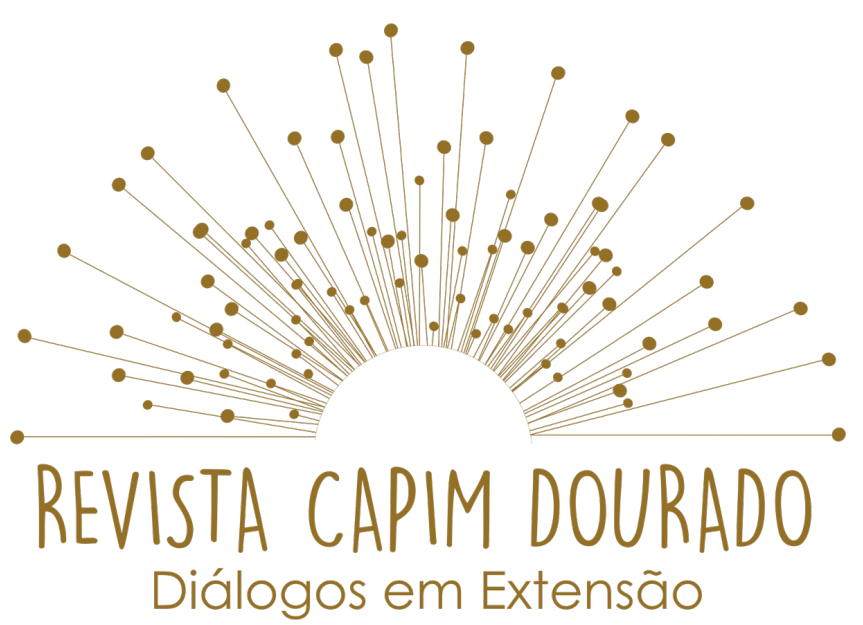

ISSN n² 2595-7341

Vol. 3, n. 1, Janeiro-Abril, 2020

DOI: http://dx.doi.org/10.20873/uft.2595-7341.2020v3n1p210

FERNÁNDEZ PENAS, M. EL CINE COMO CREADOR DE IDENTIDADES NACIONALES. Un recorrido por el cine vasco de los años ochenta a través de la filmografía del cineasta Pedro Olea. Revista Observatório, v. 2, n. 3, p. 102-118, 31 ago. 2016.

FONSECA, V. A. DA. HISTÓRIA ESCOLAR, CINEMA BRASILEIRO E HISTÓRIA PÚBLICA: caminhos de uma memória. Revista Observatório, v. 3, n. 2, p. 92-112, 8 abr. 2017.

KPOHOLO, S. F. F.; FREITAS, M. T. DE A. O CINEMA AFRICANO TECENDO REDES EDUCATIVAS E DE SUJEITOS NA FORMAÇÃO DE PROFESSORES NA MUNICIPALIDADE DE JUIZ DE FORA. Revista Observatório, v. 4, n. 5, p. 557-578, 1 ago. 2018.

KURTZ, A. S. HIBRIDIZAÇÃO E O JORNALISMO CAMALEÔNICO. Revista Observatório, v. 2, n. 5, p. 310-333, 25 dez. 2016.

LANGIE, C.; RODRIGUES, C. G. POR UMA PEDAGOGIA DA CRIAÇÃO COM O CINEMA BRASILEIRO: Curadoria e expansão do repertório. Revista Observatório, v. 4, n. 6, p. 704-728, 8 out. 2018.

LONGHI, L. EL MOMENTO DE LA VERDAD (ROSI, 1965): fragmentos de España. Revista Observatório, v. 2, n. 3, p. 83-101, 31 ago. 2016.

MACHADO, S. DE S. QUANDO TODAS AS CORES DOS CINEMAS SÃO O AZUL, A COR MAIS FRIA: Uma Análise Sobre Produções Audiovisuais e Gênero. Revista Observatório, v. 3, n. 1, p. 105-130, 30 mar. 2017.

MALDONADO, M. M. C.; SANTOS, J. DE D. DOS. PENSANDO CURRÍCULO COMO PRÁTICA DE LIBERDADE: entre concepções de infâncias representadas em filmes e narrativas cotidianas de praticantespensantes da educação. Revista Observatório, v. 5, n. 1, p. 94-109, 14 jan. 2019.

MARTINEZ, M. Reflexões sobre Jornalismo e História Oral: um campo com mais convergências do que dissonâncias. Revista Observatório, v. 2, n. 1, p. 75-91, 1 maio 2016.

MIGLIORIN, Cezar. et. al. Inventar com a diferença, Niteroi, Editora da UFF, 2 


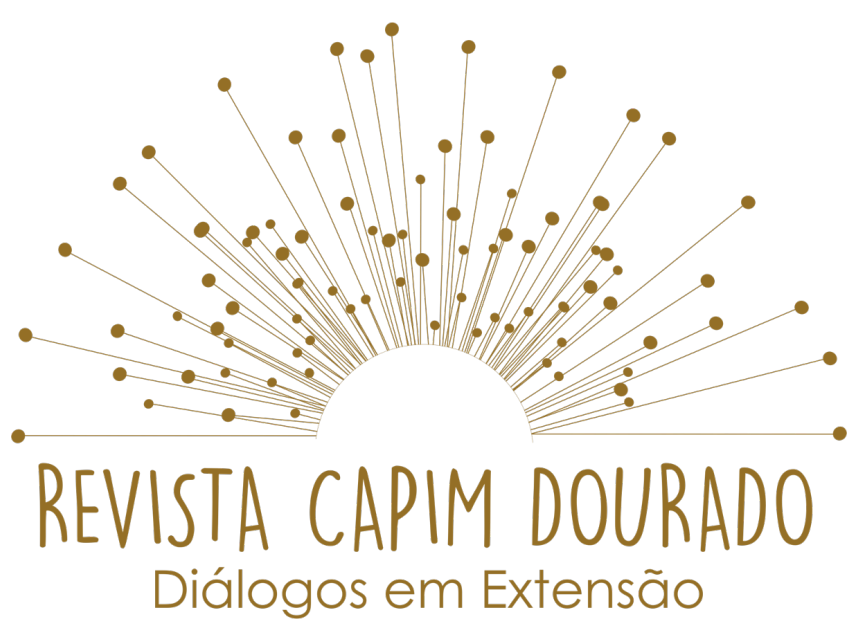

ISSN n² 2595-7341

Vol. 3, n. 1, Janeiro-Abril, 2020

DOI: http://dx.doi.org/10.20873/uft.2595-7341.2020v3n1p210

MUYLAERT MAGER, J.; MAUAD, A. M. EM CARTAZ: festivais de cinema de arquivo - preservação e público. Revista Observatório, v. 3, n. 2, p. 283-308, 1 abr. 2017. NOGUEIRA, W. DE S. CINEMA NO AMAZONAS: o imaginário colonizado navegando numa sociologia de ausências e emergências. Revista Observatório, v. 2, n. 5, p. 93-120, 25 dez. 2016.

ROPERO, J. M. P.; SILVA, J. N. DA; PORTO JUNIOR, F. G. R. NAS FRONTEIRAS DA HISTÓRIA: Memória, Gênero e Cinema em Europa e América. Revista Observatório, v. 2, n. 3, p. 20-27, 31 ago. 2016.

SILVA, F. B. SOBRE AS PERGUNTAS QUE PODEMOS FAZER AOS ARQUIVOS VISUAIS: por uma história pública, comunicação e ensino. Revista Observatório, v. 3, n. 2, p. 219-240, 1 abr. 2017.

SOUZA, P. C. L. DE. CINECLUBE ESPORTE E SOCIEDADE: cinema, comunicação e entretenimento em um projeto de extensão. Revista Observatório, v. 5, n. 4, p. 197-222, 1 jul. 2019.

VEIGA, A. M. A história oral visita o cinema: Que bom te ver viva e Los Rubios. Revista Observatório, v. 2, n. 1, p. 118-137, 1 maio 2016. 